\title{
New Method for Examining Association Between Obesity and Diabetes With Age Among Korean Adults
}

Nam Lyong Kang ( $\sim$ nlkang@pusan.ac.kr)

Pusan National University

\section{Research Article}

Keywords: Diabetes, Obesity, Body mass index, Waist-to-height ratio, lump mean value.

Posted Date: August 5th, 2021

DOl: https://doi.org/10.21203/rs.3.rs-764147/v1

License: (c) (i) This work is licensed under a Creative Commons Attribution 4.0 International License.

Read Full License 


\section{Title:}

\section{New method for examining association between obesity and diabetes with age among Korean adults}

\section{Author:}

Nam Lyong Kang*

Department of Nanomechatronics Engineering, Pusan National University, Busan, 46241, Republic of Korea

\section{Corresponding author:}

Nam Lyong Kang, Department of Nanomechatronics Engineering, Pusan National University, Busandaehang-ro 63 beon-gil 2, Geumjeong-gu, Busan 46241, Republic of Korea E-mail: nlkang@pusan.ac.kr

\section{Running Title:}

New method for examining association between 


\begin{abstract}
This study examined the age-dependence of the association between diabetes and obesity among Korean adults. The data from the Seventh Korean National Health and Nutrition Examination Survey (2017) were analyzed. This paper considered the body mass index (BMI) and waist-to-height ratio (WHT2R) as obesity indices and the fasting blood glucose (FBG) as a diabetes index and used their lump mean values and the regression method. The WEHT2R was a more suitable index for examining the FBG than the BMI. The increase in the WHT2R of females was more sensitive to age than that of males. In contrast, the increase in the FBG of males was more sensitive to age than that of females. The ages that FBG increased to $100.0 \mathrm{mg} / \mathrm{DL}$ were 44.7 and 60.5 years for males and females, respectively. Korean adults should reduce their WHT2R to prevent the excessive increase in their FBG level and Korean males should take care of their FBG from a young age. The present results can be used for a preliminary inspection of diseases, such as functional degradation of Langerhans islets and gestational diabetes
\end{abstract}

Keywords: Diabetes $\bullet$ Obesity $\bullet$ Body mass index $\bullet$ Waist-to-height ratio $\bullet$ lump mean value.

\title{
Abbreviations
}

DM: diabetes mellitus; FBG: fasting blood glucose; BMI: body mass index; WHT2R: waistto-height ratio; WC: waist circumference; LMV: lump mean value. 


\section{Introduction}

The incidence of obesity and diabetes mellitus (DM) is increasing worldwide and is a global public health concern. DM is an independent risk factor for coronary artery disease and a group of metabolic disorders characterized by high blood sugar levels [1]. DM is the most prominent disease related to the failure of blood sugar regulation that can cause many complications, such as diabetic ketoacidosis, hyperosmolar hyperglycemic state, cardiovascular disease, stroke, and chronic kidney disease [2,3]. DM is associated with a two to three-fold increase in the risk of cardiovascular disease compared to the non-diabetic population [4]. Patients with an impaired fasting glucose level have more severe coronary artery damage [5] and hyperglycemia is related to diabetic microvascular complications [6]. Cardiovascular disease is a severe complication of diabetes, and many international guidelines recommend that people with diabetes maintain a blood pressure below 140/90 $\mathrm{mmHg}$ [7].

Diabetes is classified mainly into two groups: type 1 and type 2 . Type 1 diabetes occurs mainly in children, and patients with type 1 diabetes are generally not obese [8]. In contrast, type 2 diabetes is associated with an increased prevalence of obesity among all age groups [9]. Type 1 diabetes is characterized by the loss of insulin-producing beta cells in the pancreatic islets. Type 2 diabetes is characterized by insulin resistance that may be combined with reduced insulin secretion [10]. Several lifestyle factors, such as obesity, lack of physical activity, poor diet, and stress, are important to developing type 2 diabetes [11]. Type 1 diabetes has no known preventive measures, whereas Type 2 diabetes can often be prevented or delayed by maintaining normal body weight, engaging in physical activity, and eating a healthy diet [12].

This study examined the age-dependence of the relationship between obesity and the fasting blood glucose (FBG) level, which is the most fundamental indicator of diabetes [13]. An impaired FBG is an intermediate state of abnormal glucose regulation that increases the risk of developing diabetes and associated vascular disease [14, 15]. Obesity is a major worldwide epidemic and a significant risk factor for DM. Moreover, it is a factor in hypertension, dyslipidemia, and cardiovascular damage [16, 17]. This study considered the body mass index (BMI) and waist-to-height ratio (WHT2R) as obesity indices. The BMI is a good measure of general adiposity [18], and an above-normal BMI is an established risk factor for ischemic heart disease, stroke, and carcinomas [19]. 
The WHT2R is a new obesity index presented by the present author that is defined as the waist circumference (WC) divided by the square of the height [20], considering that the WC is associated more with cardio-metabolic mortality than the BMI, and height has an inverse association with mortality [21, 22]. This paper used the lump mean values (LMVs) of the FBG

and obesity because the FBG varies with obesity in a highly complex manner and thus it is almost impossible to examine the association between the FBG level and obesity individually. For that purpose, male and female subjects were divided into groups with two successive ages.

\section{Methods}

\section{Design and participants}

The study sample was obtained from the public-use releases of the Seventh Korean National Health and Nutrition Examination Survey in 2017 (KNHANES VII-2, approval number 117002). KNHANES was designed to be a nationally representative cross-sectional survey and was conducted by the Division of Chronic Disease Surveillance of the Korea Centers for Disease Control and Prevention (KCDCP) to examine the health and nutritional status of the population. Informed consent was obtained from all participants at the time of enrollment, and the protocol was approved by the institutional review board (IRB) in the KCDCP

The final study cohort was 1788 males and 2301 females from 4261 subjects aged 20 to 65 years, excluding subjects with extreme BMI, WHT2R, or FBG values to investigate the association between obesity and FBG in Korean adults. The excluded ranges were as follows: BMI $<15.62 \mathrm{~kg} / \mathrm{m}^{2}$ or $>32.93 \mathrm{~kg} / \mathrm{m}^{2}$ for males and BMI $<15.37 \mathrm{~kg} / \mathrm{m}^{2}$ or $>32.95 \mathrm{~kg} / \mathrm{m}^{2}$ for females; WHT2R $<20.05 \times 10^{-4} \mathrm{~cm}^{-1}$ or $>40.99 \times 10^{-4} \mathrm{~cm}^{-1}$ for males and WHT2R $<22.0 \times 10^{-4} \mathrm{~cm}^{-1}$ or $>43.0 \times 10^{-4} \mathrm{~cm}^{-1}$ for females; FBG $<68.0 \mathrm{mg} / \mathrm{dL}$ or $180.0 \mathrm{mg} / \mathrm{dL}$ for males and FBG $<68.0 \mathrm{mg} / \mathrm{dL}$ or $179.0 \mathrm{mg} / \mathrm{dL}$ for females.

\section{Statistical analysis}

This study investigated the age-dependence of the associations of the BMI and WHT2R with FBG considering their LMVs given in the Supplementary File and using Microsoft Excel 2014, SPSS (version 25), and regressions in Sigmaplot 14. Each lump was composed of subjects with two successive ages, and the number of subjects contained in each lump was slightly different according to age. 


\section{Results}

\section{Age-dependence of association between BMI and FBG}

Figure 1 presents the LMVs of the BMI and FBG of males with respect to age.

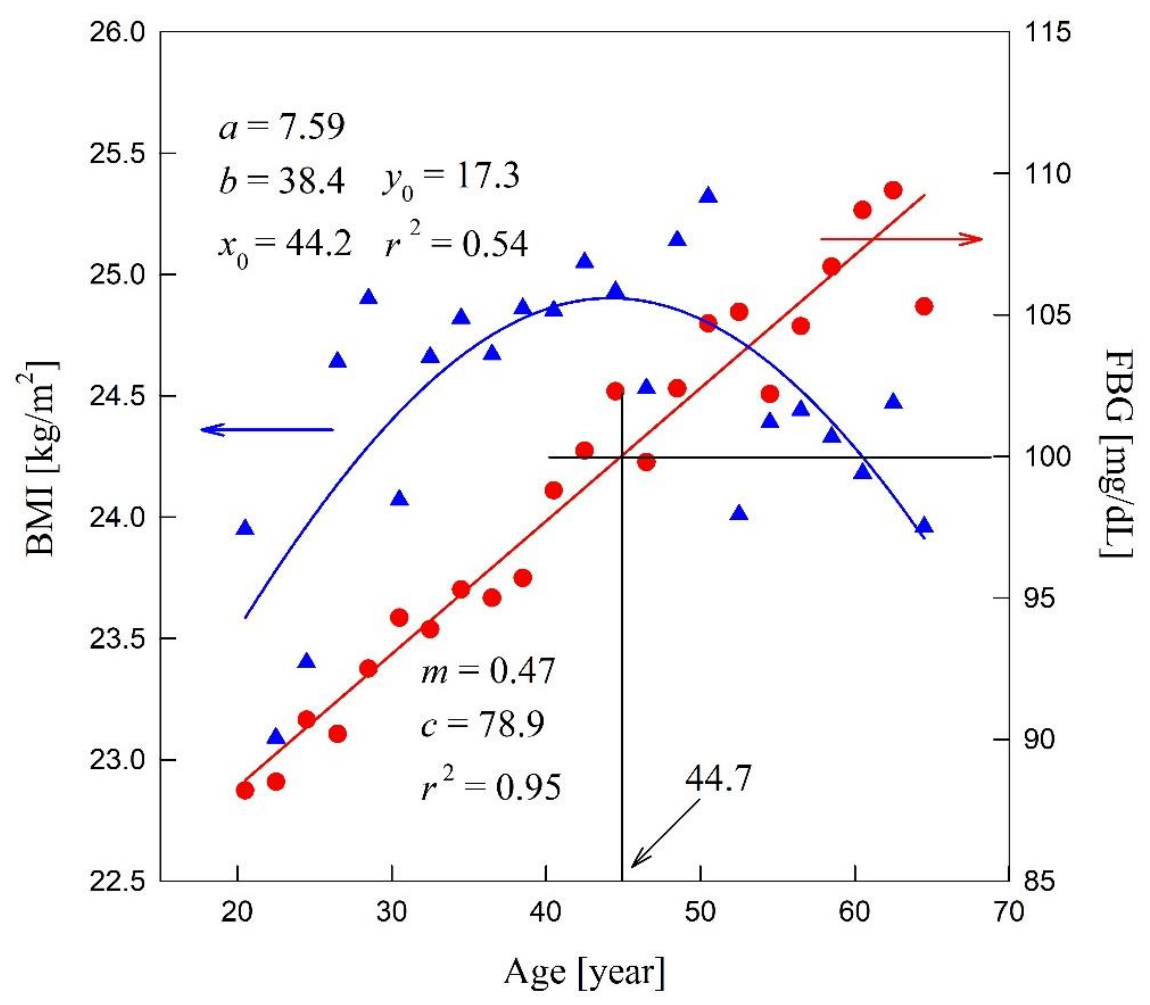

Figure 1: BMI and FBG of males with respect to age.

The BMI of males (blue triangles) increased to a maximum value of $24.9 \mathrm{~kg} / \mathrm{m}^{2}$ with age less than 44.5 years and then decreased, so it was fitted to the blue (Gaussian) curve given by the following equation:

$$
y(x)=y_{0}+\operatorname{aexp}\left[-\frac{\left(x-x_{0}\right)^{2}}{2 b}\right]
$$

where $x$ is age, $y(x)$ is the LMV of BMI, and $y_{0}$ is the minimum value of $y(x)$ when the constant $a$ is positive. $\sqrt{b}$ is the standard deviation that determines the width of the distribution. $x_{0}$ is the $x$ value corresponding to the maximum value of $y(x)$. The parameters $a, b, x_{0}$, and $y_{0}$ are shown in the figure. $r^{2}$ is the coefficient of determination. The BMI of males appeared 
to decrease with age after 44.5 years of age because they reduce their weight by controlling their food intake and physical activity for good health.

The FBG of males (red circles) increases continuously with age, so it was fitted to the red straight line expressed as

$$
y(x)=m x+c
$$

where $x, c, m$, and $y(x)$ are age, a constant, the slope, and the LMV of the FBG, respectively. The parameters $m$ and $c$ are shown in the figure. $r^{2}$ is the coefficient of determination. The goodness of fit for linear regression was sufficient according to $r^{2}$.

The regressed value of the FBG of males increased from $88.6 \mathrm{mg} / \mathrm{dL}$ to $109.2 \mathrm{mg} / \mathrm{dL}$ with increasing age from 20.5 years old to 64.5 years old. Hence, the increase in the FBG of males with age before 44.5 years of age is associated with an increase in BMI. The FBG of males increased to $100.0 \mathrm{mg} / \mathrm{DL}$ when they were 44.7 years old.

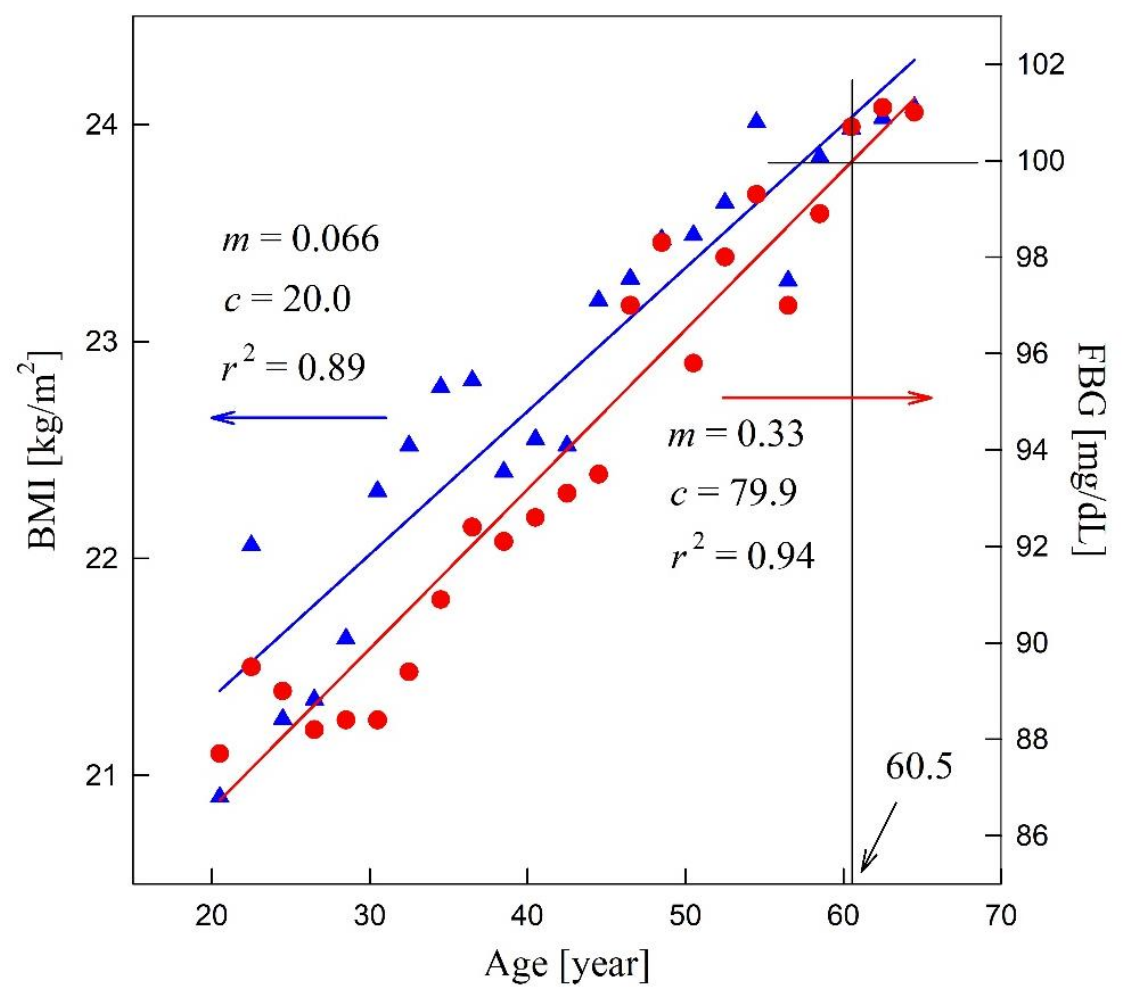

Figure 2: $\mathrm{BMI}$ and $\mathrm{FBG}$ of females with respect to age.

Figure 2 shows that both the BMI (blue triangles) and FBG (red circles) of females increased continuously with age. Hence, they were fitted to the straight lines given by Eq. (2). Therefore, the increase in the FBG of females with age is associated with an increase in BMI. 
The regressed values of the BMI and FBG of females increased from $21.4 \mathrm{~kg} / \mathrm{m}^{2}$ to $24.3 \mathrm{~kg} / \mathrm{m}^{2}$ and from $86.7 \mathrm{mg} / \mathrm{dL}$ to $101.3 \mathrm{mg} / \mathrm{dL}$ with age from 20.5 to 64.5 years old, respectively. The parameters $m$ and $c$ are shown in the figure, and the goodness of fit for linear regression was sufficient according to the coefficient of determination $\left(r^{2}\right)$. The FBG of females increased to $100.0 \mathrm{mg} / \mathrm{DL}$ when they were 60.5 years of age.

\section{Age-dependence of association between WHT2R and FBG}

The WHT2R (blue triangles) and FBG (red circles) of females and males are associated with WHT2R because they increase continuously with age (Figs. 3 and 4). Thus, the WHT2Rs and FBGs of males and females were fitted to straight lines given by Eq. (2). The increase in FBG with age is associated with an increase in WHT2R for both males and females. The FBG levels in Figs. 3 and 4 are the same as those in Figs. 1 and 2. The parameters $m$ and $c$ are shown in the figures, and the goodness of fit for linear regression was sufficient according to the coefficient of determination $\left(r^{2}\right)$.

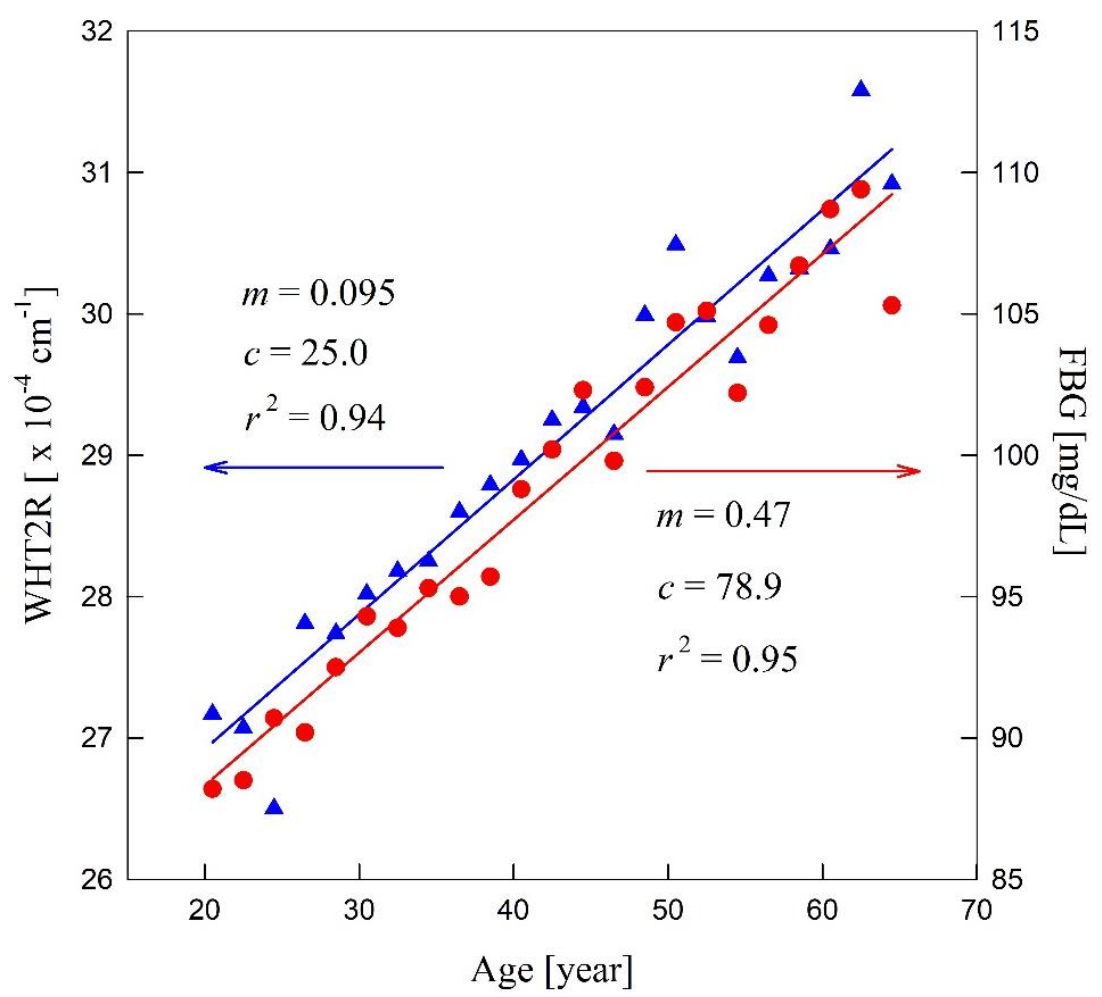

Figure 3: WHT2R and FBG of males with respect to age. 


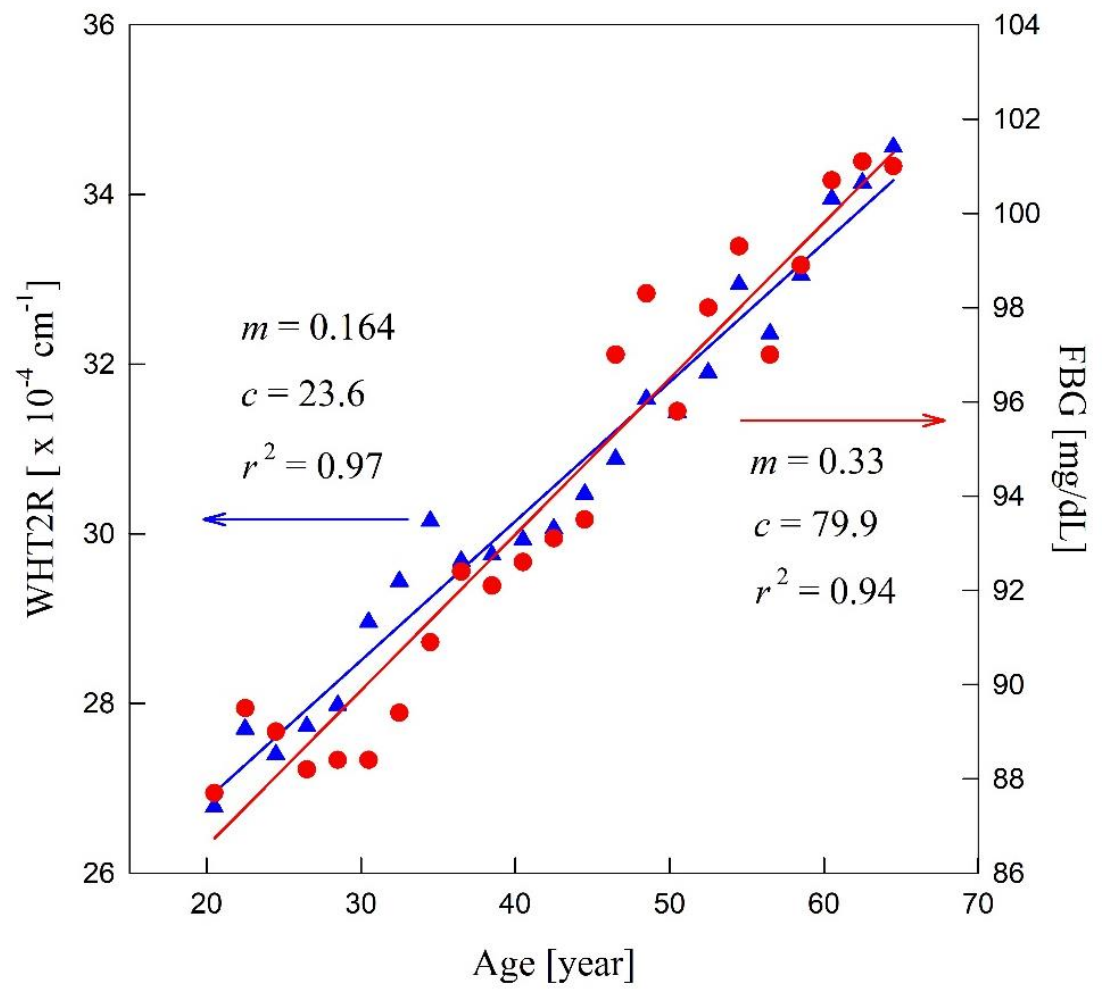

Figure 4: WHT2R and FBG of females with respect to age.

The regressed values of the WHT2R of males and females increased from $27.0 \times$ $10^{-4} \mathrm{~cm}^{-1}$ to $31.2 \times 10^{-4} \mathrm{~cm}^{-1}$ and from $27.0 \times 10^{-4} \mathrm{~cm}^{-1}$ to $34.2 \times 10^{-4} \mathrm{~cm}^{-1}$, respectively, with age increases from 20.5 to 64.5 years old. The WHT2R of females increased with age more rapidly than that of males because the slope $\left(m=0.164 \times 10^{-4} \mathrm{~cm}^{-1}\right.$. year $\left.^{-1}\right)$ of the straight line for females was larger than that $\left(m=0.095 \times 10^{-4} \mathrm{~cm}^{-1}\right.$. year $^{-1}$ ) for males. In contrast, the FBG of males increased with age more rapidly than that of females because the slope $(m=0.47 \mathrm{mg} / \mathrm{dL} \cdot$ year $)$ of the straight line for males was larger than that $(m=0.33 \mathrm{mg} / \mathrm{dL} \cdot$ year $)$ for females.

\section{Discussion}

The age dependence of the FBG and its associations with the BMI and WH2TR were investigated using their LMVs. The WHT2R of males, the BMI and WHT2R of females, and the FBG of males and females increased linearly with age, but BMI of males increased with age before 44.5 years of age and then decreased. Hence, the LMVs of the WHT2R of males, 
the BMI and WHT2R of females, and the FBG of males and females with respect to age were fitted to straight lines given by Eq. (2). In contrast, the BMI of males was fitted to a Gaussian curve given by Eq. (1). This means that the WHT2R is a more suitable index to examine the FBG level than the BMI because the FBG level of females is associated with both the BMI and WHT2R, whereas for males, the FBG level is associated only with the WHT2R.

The increase in the WHT2R of females is more sensitive to age than the increases in the WHT2R of males because the slope $\left(m=0.164 \times 10^{-4} \mathrm{~cm}^{-1} \cdot \mathrm{year}^{-1}\right)$ of the straight line of the WHT2R for females is larger than that $\left(m=0.095 \times 10^{-4} \mathrm{~cm}^{-1} \cdot\right.$ year $\left.{ }^{-1}\right)$ for males. The increase in the FBG of males is more sensitive to age than the increase in the FBG of females because the slope $(m=0.47 \mathrm{mg} / \mathrm{dL} \cdot$ year $)$ of the straight line for the FBG of males is larger than that $(m=0.33 \mathrm{mg} / \mathrm{dL} \cdot$ year) for females. The ages that the FBG increases to $100.0 \mathrm{mg} / \mathrm{DL}$ were 44.7 and 60.5 years of age for males and females, respectively. This means that males need to take care of their FBG level from an early age.

The fat level of females results in a more rapid increase in BMI than males because females include more fat in their BMI than males. In contrast, the fat of males increases although their BMI decreases after 44.5 years old because more muscle is included in their BMI than in females. This means that the fat of males increases and muscle decreases as the BMI decreases after 44.5 years of age because Korean men reduce their BMI after 44.5 years of age by reducing their weight by controlling food intake and exercising for good health, but their WHT2R or abdominal obesity increases with age. In general, the female hormone (estrogen) blocks the accumulation of visceral fat in the body, particularly before menopause. Thus, males have more visceral fat, and females have more subcutaneous fat. Therefore, the FBG of males increases with age after 44.5 years old because their visceral fat increases with age, even though their BMI decreases, whereas the FBG of females increases with age because their visceral fat increases with age according to the increase in BMI

The WHT2R includes the WC in the numerator of its definition, which is associated with abdominal obesity, so fat increases with increasing WHT2R. This confirms that the FBG is associated with obesity. The WHT2R of males increases after 44.5 years of age because their abdominal obesity increases even though their weight decreases. The WHT2R of Korean women before the age of 30 years was distorted because they decrease their WC by controlling 
food intake and exercising for good body shape (red dots in Figs. 2 and 4). Therefore, the FBG level of females before the age of 32 years is distorted.

\section{Conclusion}

This paper recommends that Korean adults reduce their WHT2R to restrain the excessive increase of their FBG level. Moreover, Korean males should take care of their FBG from an early age. The present result can be used for a preliminary inspection of diseases, such as the function degradation of Langerhans islets and gestational diabetes because the FBG levels of Korean adults above the red straight lines in Figs. 1-4 are higher than those of the same age. Furthermore, the present method can be applied to examine the associations of obesity with neutral fat or cholesterol level.

Acknowledgements The author wishes to thank the Korea Centers for Disease Control and Prevention for providing the data from the Korea National Health and Nutrition Examination Survey 2016-2017.

Author contributions NLK is responsible for the idea, design, implementation, and analysis of the study. The author read and approved the final manuscript.

Funding This research did not receive any specific grants from funding agencies in the public, commercial, or non-profit sectors.

Data availability Data are available from the Korea National Health and Nutrition Examination Survey (KNHANES) conducted by the Korea Centers for Disease Control and Prevention (KCDCP) and are freely available from KCDCP (https://knhanes.cdc.go.kr).

\section{Compliance with Ethical Standards}

Conflict of interest The author declares that he has no conflicts of interests. 
Consent for publication Not applicable.

Ethics approval Ethics approval was not required as this study was performed using the public-use releases of a nationally representative cross-sectional survey. This article does not contain any studies with human or animal participants performed by the author.

\section{References}

1. World Health Organization (2014) Archived from the original on 31 March 2014. Retrieved April 2014.

2. Kitabchi AE, Umpierrez GE, Miles JM, Fisher JN (2009) Hyperglycemic crises in adult patients with diabetes. Diabetes Care 32:1335-1343.

3. Saedi E; Gheini MR; Faiz F; Arami MA (2016) Diabetes mellitus and cognitive impairments. World J Diabetes 7:412-422.

4. Kannel WB, McGee DL (1979) Diabetes and cardiovascular disease. Framingham study. JAMA 241:2035-2038.

5. Gurudevan S, Garg P, Malik S, et al (2016) Impaired fasting glucose is associated with increased severity of subclinical coronary artery disease compared to patients with diabetes and normal fasting glucose: evaluation by coronary computed tomographic angiography. BMJ Open 6: e005148

6. TUK Prospective Diabetes Study (UKPDS) Group Turner RC, Holman RR., Cull CA., et al (1998) Intensive blood-glucose control with sulphonylureas or insulin compared with conventional treatment and risk of complications in patients with type 2 diabetes (UKPDS 33). Lancet 352:837-853.

7. Mitchell S, Malanda B, Damasceno A, et al (2019) A Roadmap on the Prevention of Cardiovascular Disease Among People Living With Diabetes. Glob Heart 14:215-240.

8. American Diabetes Association (2007) Diagnosis and classification of diabetes mellitus. Diabetes Care 30(suppl 1):S42-S47.

9. Ershow AG (2009) Environmental influences on development of type 2 diabetes and obesity: challenges in personalizing prevention and management. J Diabetes Sci Technol 3:727-734. 
10. Gardner D, Shoback D (2011) Greenspan's basic and clinical endocrinology ( $9^{\text {th }}$ ed). New York: McGraw-Hill Medical Chapter 17

11. Williams textbook of endocrinology (12thed) (2011) Elsevier/Saunders 1371-1435.

12. Alustiza E, Perales A, Mateo-Abad M, et al (2020) Tackling risk factors for type 2 diabetes in adolescents: PRE-STARt study in Euskadi. Madrid: Anales de Pediatría Dec 30 (online)

13. Zsuga J, Gesztelyi R, Kemeny-Beke A, et al (2012) Different effect of hyperglycemia on stroke outcome in non-diabetic and diabetic patients-a cohort study. Neurol Res 34:7279.

14. Wat NM, Lam TH, Janus ED, Lam KS (2001) Central obesity predicts the worsening of glycemia in southern Chinese. Int Journal Obes Relat Metab Disord 25:1789-1793.

15. de Vegt F, Dekker JM, Jager A, et al (2001) Relation of impaired fasting and postload glucose with incident type 2 diabetes in a Dutch population: the hoorn study. JAMA 285:2109-2113.

16. Loehr LR, Rosamond WD, Poole C, et al (2009) The association of multiple anthropometrics of overweight and obesity with incident heart failure: The atherosclerosis risk in communities study. Circulation: Heart Failure 2:18-24.

17. Turkbey EB, McClelland RL, Kronmal RA, et al (2010) The impact of obesity on the left ventricle: the multi-ethnic study of atherosclerosis (MESA). JACC Cardiovasc Imaging $3: 266-274$.

18. Molarius A. Seidell JC (1998) Selection of anthropometric indicators for classification of abdominal fatness-a critical review. Int J Obes Relat Metab Disord 22:719-727.

19. Prospective Studies Collaboration; Whitlock G, Lewington S, Sherliker P, et al (2009) Body-mass index and cause-specific mortality in 900000 adults: collaborative analyses of 57 prospective studies. Lancet 373(9669):1083-1096.

20. Kang NL (2021) Association between obesity and blood pressure in common Korean people. Vasc Health Risk Manag 17:371-377.

21. Langenberg C, Shipley MJ, Batty GD, Marmot MG (2005) Adult socioeconomic position and the association between height and coronary heart disease mortality: findings from 33 years of follow-up in the Whitehall Study. Am J Public Health 95:628-632. 
22. Petursson H, Sigurdsson JA, Bengtsson C, Nilson TIL, Getz L (2011) Body configuration as a predictor of mortality: comparison of five anthropometric measures in a 12 year follow-up of the Norwegian HUNT 2 study. PLoS One 6:e26621. 


\section{Supplementary Files}

This is a list of supplementary files associated with this preprint. Click to download.

- scientific21supple.docx 